\title{
PERSPECTIVAS EN TORNO AL USO DE CONTINGENTES BÁRBAROS REDUCIDOS EN EL EJÉRCITO ROMANO TARDÍO
}

\author{
Fernando C. Ruchesi \\ Universidad Nacional del Nordeste - CONICET \\ fruchesi@hotmail.com
}

\begin{abstract}
El presente artículo tiene como objetivo analizar la utilización de grupos bárbaros reducidos, por parte de las autoridades imperiales, desde fines del siglo IV hasta comienzos del siglo V. En primer lugar, abordaremos cuestiones tales como el modo en que estos tipos de contingentes eran empleados en el ejército romano tardío. En segundo término, la cuestión de su integración en las estructuras imperiales en relación a los citados modos de empleo. Finalmente, analizaremos las representaciones de dichos contingentes por parte de los autores de la época.
\end{abstract}

Bárbaros / Imperio romano / Ejército / Antigüedad tardía / Grupos

\section{PERSPECTIVES ON THE USE OF SMALL BARBARIAN CONTINGENTS IN THE LATE ROMAN ARMY}

The aim of this article is to analyse the use of small barbarian groups by the Roman Empire, from the end of the fourth century to the beginning of the fifth. I will address topics such as the modalities of use of these barbarian contingents in the late Roman army. Secondly, I will enquire on their integration into the imperial structures according to such modalities. Finally, I will also focus on the representations of such contingents by the contemporary authors.

Barbarians / Roman Empire / Army / Late Antiquity / Groups 


\section{Introducción}

$\mathrm{L}$

a muerte del emperador Teodosio y la posterior división administrativa del imperio dieron paso a un período de inestabilidad que traería consecuencias económicas y políticas negativas para el Estado romano en el largo plazo. Todo esto se debió, en gran medida, a la incapacidad que demostraban los hijos del mencionado Teodosio para gobernar, como así también a los ambiciosos planes de gobierno que deseaban llevar a cabo los militares y las facciones de la corte ${ }^{1}$. A esto debemos sumar el desarrollo de varias insurrecciones institucionales que se iniciaron a partir de la década de 380: Teodosio debió enfrentar a dos usurpadores (Magno Máximo y Eugenio) ${ }^{2}$ y sus hijos habrían de detener a otros más (Constantino III y Jovino, por ejemplo) ${ }^{3}$. A este último factor debemos añadir la presencia cada vez más notoria de los bárbaros, tanto dentro como fuera de los límites del imperio. En muchas ocasiones, estas comunidades buscaban tierras para asentarse en el interior del territorio romano, debido a la presión que habían experimentado a manos de otros contingentes en las regiones situadas más allá de las fronteras del Rin y del Danubio ${ }^{4}$.

En este contexto de inicios del siglo V, las gentes barbarae pasaron a cumplir funciones que resultaron fundamentales para el aparato imperial. Su participación en apoyo del ejército romano durante el desarrollo de estas operaciones fue, sin duda, una de las novedades de este período. Este fue el resultado del recurso cada vez más frecuente a este tipo de efectivos, por parte de las autoridades imperiales, para poder hacer frente a sus problemas políticos internos y externos ${ }^{5}$.

Este trabajo tiene como fin analizar las modalidades del accionar de grupos reducidos de efectivos bárbaros reclutados por los romanos entre fines del siglo IV y comienzos del V, es decir, el período correspondiente al gobierno de Teodosio y la supremacía de Estilicón en el Occidente romano. En este sentido, nos centraremos en los modos en que estos tipos de contingentes eran utilizados en el ejército romano tardío. En segundo lugar, abordaremos la cuestión de su integración en las estructuras imperiales en relación a los citados modos de utilización y, por último, analizaremos las representaciones de dichos contingentes por parte de los autores de la época.

\footnotetext{
1 BLockley (2008: 189).

2 JoNes (1964: 158-161).

3 ARCE (2007: 33-35; 73-74).

4 Heather (1995).

5 Liebeschuetz (1993: 267)
} 


\section{El contexto de la llegada de los bárbaros y su reclutamiento en el imperio}

Es preciso comprender el reclutamiento masivo de bárbaros en el contexto del siglo IV. El enrolamiento de este tipo de efectivos se enmarca en las reformas que habían realizado los emperadores Diocleciano y Constantino en el ámbito castrense, ya desde fines del siglo III y comienzos del IV (modificaciones que llegaron a su culminación con la división del ejército en comitatenses y limitanei). A estos cambios debemos añadir las transformaciones que llevó a cabo Teodosio (378-395) durante su gobierno, como por ejemplo, la partición del cuerpo militar en ejércitos regionales: dos de ellos estarían situados en Italia, a la entera disposición del emperador mientras que los otros tres estarían estacionados en la frontera oriental, Tracia e Iliria ${ }^{6}$.

En este marco administrativo-militar, una de las modalidades que tuvo el enrolamiento de guerreros bárbaros ${ }^{7}$ en el cuerpo castrense romano está vinculada al proceso que algunos académicos designan como "deditio-restitutio-foedus", para el caso de los federados. El primer vocablo alude a la rendición o sumisión de una comunidad tras un combate. La restitutio era el procedimiento por el cual se restauraba el orden y el foedus, finalmente, era el acuerdo que se establecía entre el pueblo vencido y el imperio. Tras este último paso, la gens bárbara en cuestión pasaba a formar parte de los federados: desde ese momento, sus miembros eran conocidos como foederati y debían servir militarmente al Estado romano. A cambio, el gobierno imperial les otorgaba pagos y favores (en especial, a los caudillos de estos contingentes). De acuerdo con Peter Heather, cada foedus variaba, dependiendo del grupo con el cual se pactaba. Este historiador afirma, además, que una vez que estos contingentes eran sometidos por el ejército romano, pasaban a formar parte de la estructura imperial, incluso si no se llegaba a imponer una organización provincial en el territorio en el que esa comunidad habitaba y su orden social continuaba inalterado ${ }^{8}$.

6 Jones (1964: 609).

7 Las gentes barbarae también participaban de un reclutamiento voluntario para engrosar las filas de los ejércitos romanos. Francisco Guzmán Armario proporciona algunos detalles de este tipo de enrolamiento en relación al testimonio de Amiano Marcelino, siendo ejemplo de ello los numerosos casos de oficiales con orígenes franco y alamán en el texto del antioqueno. Véase: GuZmán Armario (2000-2002: 116, 125). Asimismo, existen otras categorías vinculadas al enrolamiento de estos grupos como la de laeti. En la actualidad, se considera que estos laeti fueron grupos de guerreros bárbaros instalados en territorio romano con sus familias; se les proporcionaban tierras para trabajar (normalmente en las proximidades del limes) y, a cambio, debían proveer reclutas para el ejército y vigilar las fronteras. Véase: LIEBESCHUETZ (2007: 486); SOUTHERN (2006: 259-260).

HEATHER (1997: 59, 63, 65-66, 69-70). 
En relación con estos procesos vinculados al reclutamiento de grupos no romanos, el reinado de Teodosio se caracterizó por el conocido foedus del año 382, establecido con los godos ${ }^{9}$. Esto trajo como consecuencia la incorporación progresiva de los guerreros bárbaros en el ejército romano durante las décadas de 380 y 390. Este pacto fue quizás el producto del resultado adverso de la Batalla de Adrianópolis, del año 378: tras la conocida contienda, el imperio perdió casi la totalidad del ejército oriental ${ }^{10}$. Esta fue una de las causas del viraje de la política exterior de Teodosio hacia el reclutamiento de bárbaros, puesto que este gobernante tuvo que reconstruir con celeridad el cuerpo militar perdido en Adrianópolis ${ }^{11}$.

Este foedus presentaba cierta originalidad para el momento en que fue acordado: por un lado, era la primera vez que se le permitía a comunidades bárbaras, como las de los tervingios y greutungos establecerse en el interior del imperio, recibiendo para ello territorios para instalarse ${ }^{12}$. Además, la estructura social de estos contingentes permaneció inalterada. A cambio de estas concesiones, los godos debían contribuir con efectivos para el ejército romano ${ }^{13}$. La novedad se encontraba en que tales efectivos serían liderados por sus propios jefes y no por oficiales imperiales. Esto representó un punto crucial en las relaciones entre godos y romanos ${ }^{14}$. Según Liebeschuetz, este foedus se convirtió en el modelo para los acuerdos subsiguientes a lo largo del siglo $\mathrm{V}^{15}$. A partir de estos lineamientos, los romanos pactaron a menudo con los visigodos en el período 395-418. Por lo general, los líderes godos recibían un cargo en la jerarquía castrense y un salario a cambio de prestar servicios militares para el imperio. En muchas ocasiones estas alianzas eran deshechas debido al incumplimien-

9 STICKLER (2007a: 505).

10 HEATHER (1994: 125-126); WheEler (2007: 256).

11 Elton (1997: 152-153); Liebeschuetz (1990: 26).

12 Heather (1994: 179); Jones (1964: 157). Respecto de la división entre tervingios y greutungos, para Peter Heather, esa distinción carecía ya de sentido durante la época en que Eunapio de Sardes y Sinesio de Cirene escribieron sus obras. El autor estima que ambos grupos constituían una fuerza sin divisiones. Véase: HEATHER (1994: 15, 191-192). Por otra parte, Herwig Wolfram, la división entre los dos grupos ya habría tenido lugar hacia fines del siglo III. El historiador austríaco señala que la distinción se habría originado tras la derrota de Claudio II (268-270) y Aureliano (270-275) contra los godos que, hasta ese entonces, habrían contado con una monarquía común que englobaba a toda la tribu. Estos fueron los dos grupos estudiados por los observadores contemporáneos del mundo grecolatino: "They were familiar with the two special names of the Danubian Goths, who called themselves 'the Good', Vesi, and whom their neighbors -the 'splendid' Ostrogoths or Greutungian 'steppe and grass dwellers'- called Teruingi, "forest people'". Véase: Wolfram (2005: 46-47, 69).

13 HeAther (1994: 163).

14 Halsall (2007: 180).

15 Liebeschuetz (1990: 28).

Argos 40 (2017) ISSN 0325-4194, pp. 61-83 
to de alguna de las partes. Cuando esto ocurría, se debía normalmente a la disconformidad de los jefes bárbaros -Alarico y Ataúlfo representan dos de los ejemplos clásicos ${ }^{16}$. Creemos que este modelo de alianza por el cual una gens era asentada dentro de las fronteras del imperio a cambio de colaborar en funciones militares también fue aplicado, quizás con algunas diferencias producto del contexto, a otros grupos también en el siglo $\mathrm{V}$ (como por ejemplo, en el caso de los alanos y burgundios) ${ }^{17}$.

Ahora bien, el foedus del 382 no fue el único elemento que contribuyó al ingreso de guerreros bárbaros en la estructura militar del imperio: las fuentes hacen referencia a la existencia de oficiales bárbaros en el ejército tiempo antes de este acuerdo ${ }^{18}$. Muchos de estos personajes lograron ascender en la jerarquía castrense hasta llegar a posiciones de poder. Uno de estos casos se encuentra documentado en las Res Gestae de Amiano Marcelino. Se trata del general Silvano, un militar de origen franco que había planeado la deposición del emperador Constancio II alrededor del año $355^{19}$. Otros ejemplos de este tipo están representados por las figuras de Merobaudes, Bauto y Arbogastes ${ }^{20}$-todos ellos también francos ${ }^{21}-$ que se desempeñaron en el ejército de Occidente.

Como veremos a continuación, las autoridades romanas adoptaron una tendencia que consistía en utilizar a este tipo de contingentes en los conflictos políticos internos y externos.

16 Halsall (2007: 191-193, 220).

17 Alanos: Bachrach (1973: 74-75); burgundios: KaISER (2004: 32, 213); Goffart (1980: 127-161).

18 GEARY (1988: 78-79) afirma, por ejemplo, que el Imperio comenzó a reclutar a guerreros francos en el norte de la Galia ya desde el siglo III.

19 Amiano Marcelino, XV.5. Para la obra de Amiano Marcelino, sigo la edición de Rolfe (1935). En el caso de Silvano, Guzmán Armario plantea que su figura es la de un "comodín histórico", es decir, fue utilizada por Amiano Marcelino dependiendo de las situaciones en cuestión, por lo general, para su panegírico sobre Juliano. Véase: GuzMÁn ARMARIo (20002002: 136-138).

20 Arbogastes, por ejemplo, llevó a cabo una insurrección y designó como emperador a Eugenio, derrocando a Valentiniano II. Véase: O'Flynn (1983: 6-7).

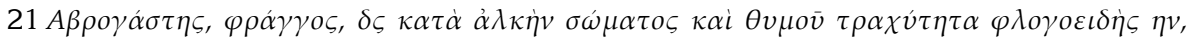

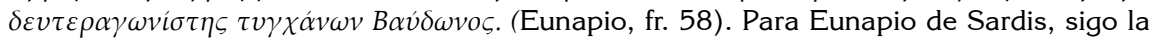
edición de Blockley (1983).

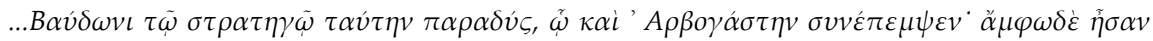

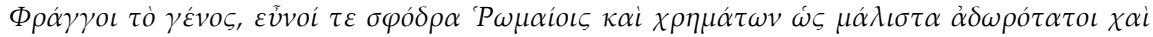

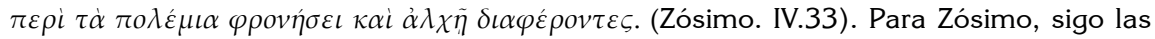
ediciones de Paschoud (1971), Candau Morón (1992) y Ridley (1982). Véase, además: O'Flynn (1983: 2). 


\section{El caso de Odoteo y los greutungos ${ }^{22}$}

Como hemos mencionado con anterioridad, tanto en vísperas de la batalla de Adrianópolis como luego de su desenlace, varios grupos bárbaros lograron cruzar la frontera romana y muchos de ellos, asimismo, llevaron a cabo pillajes y actividades de saqueo. Entre estos numerosos contingentes, contamos con el caso de los greutungos, descritos de esta manera por el historiador bizantino Zósimo. De acuerdo con este autor, durante el reinado de Teodosio se produjo una invasión por parte de un grupo extranjero. Estos guerreros eran comandados por un caudillo de nombre Odoteo. Zósimo se refiere a ellos de la siguiente manera:

Por su parte, Prómoto, comandante de la infantería estacionada en Tracia, salió con fuerzas de tierra y embarcaciones fluviales al encuentro de Odoteo, quien, al mando de numerosísimos contingentes extraídos no sólo de los pueblos vecinos al Danubio, sino también de otros más lejanos que no eran conocidos, habían avanzado con todo su ejército atravesando el río; y llevó a cabo tal masacre que se llenó de cadáveres el río y no podían contarse fácilmente los caídos en tierra ${ }^{23}$.

Otro autor contemporáneo, el poeta Claudio Claudiano, también se refirió a la llegada de los greutungos al interior del imperio:

En otro tiempo los greutungos, atreviéndose a cruzar el Danubio, abatieron un bosque para construir barcas. Tres mil embarcaciones se precipitaban a través del río llenas de espantosas tropas. Su jefe era Odoteo ${ }^{24}$.

Finalmente, el autor anónimo de la Consularia Constantinopolitana ${ }^{25}$ también se refirió a este episodio, alegando que los greutungos fueron de-

22 Si bien varias de las fuentes que citaremos a continuación presentan diversas denominaciones para referirse a este grupo, tales como grotingi o gruthungi, entre otras, apelaremos a la acepción greutungos, en español, a modo de evitar confusiones.

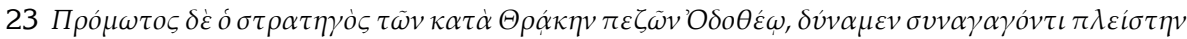

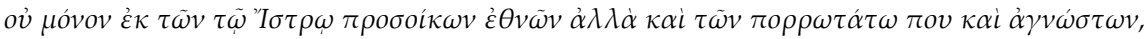

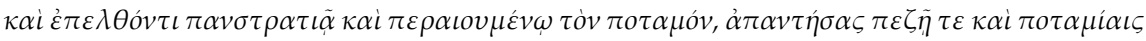

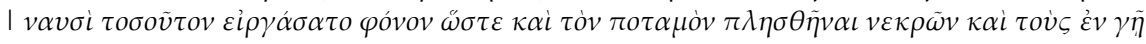

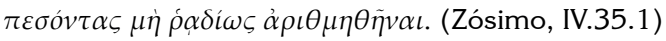

24 Ausi Danuvium quondam transnare Gruthungi in lintres fregere nemus; ter mille ruebant per fluvium plenae cuneis inmanibus alni. Dux Odothaeus erat. (Claudio Claudiano, Cuarto Consulado de Honorio, 623-626). Para las obras de Claudiano, sigo la edición de PLAutNer (1990).

25 De acuerdo con Burgess, todos los ejemplos de Consularia que llegaron a nosotros son anónimos. El autor sugiere que quizás se trate de una característica del género. Véase: BuRGESS (1993: 179). 
rrotados y luego capturados para ser llevados a la tierra de los romanos ${ }^{26}$. De cualquier manera, el documento no ofrece más detalles sobre el acontecimiento. Pese a ello, la mención de que fueron conducidos como cautivos al interior del imperio puede sernos de utilidad para comprender mejor el proceso a través del cual, algunos de estos grupos eran integrados al Estado romano para luego ser utilizados en las campañas militares.

Como podemos apreciar, sobre este Odoteo, prácticamente no sabemos nada a excepción de que era un hombre de orígenes no romanos y lideraba un contingente que habría estado constituido, a su vez, por grupos más pequeños ${ }^{27}$. De acuerdo con este pasaje de la obra de Zósimo, Prómoto derrotó a estos barbaros y causó una gran masacre. Ahora bien, en otro fragmento de la narración del mismo autor, encontramos algunos detalles más sobre este grupo:

Cerca de la misma época, un pueblo escita, desconocido para cualquiera que viviese allí, apareció desde detrás del Danubio. Los bárbaros los llamaban greutungos. Siendo muy numerosos, bien armados y renombrados por su fuerza, ellos invadieron fácilmente a los bárbaros situados entre ellos mismos y el río y llegaron al banco mismo, lugar en el que pidieron que se les permita cruzar. Prómoto, el comandante de esa región, extendió sus fuerzas tan lejos como fue posible a lo largo del río y les impidió continuar su camino ${ }^{28}$.

Como podemos apreciar, el episodio descrito por Zósimo nos recuerda, en parte, a los eventos previos que tuvieron lugar antes de la batalla de Adrianópolis: un contingente que pedía poder ingresar al imperio a las

26 Uicti atque expugnati et in Romania captiui adducti gens Greothyngiorum a nostris Theodosio et Arcadio. (Consularia Constantinopolitana, 386). Para la Consularia, sigo la edición de BuRgess (1993). En relación a la victoria obtenida sobre estos greutungos, Thomas Burns afirma que ese triunfo fue motivo de celebración en Constantinopla, en 386. La aclamación se encuentra descrita en ciertas fuentes como así también en monedas. De allí que el obelisco que Teodosio erigiese en el hipódromo de la capital oriental, en 390, presente relieves con imágenes de los bárbaros siendo derrotados. Se trataba de una demostración de que la integridad del limes fue restaurada hacia 386. Véase: BuRNs (1994: 89-90).

27 Wolfram, por ejemplo, considera que Odoteo lideraba un gran número de ostrogodos bien equipados, quienes deseaban cruzar el Danubio para convertirse en romanos. Con su establecimiento en Frigia, "the Gothicization of the Danubian provinces had spread even into Asia Minor". Véase: Wolfram (2005: 124).

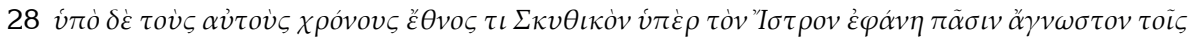

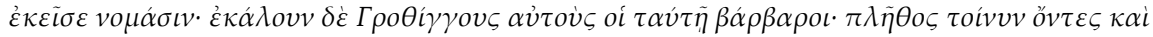

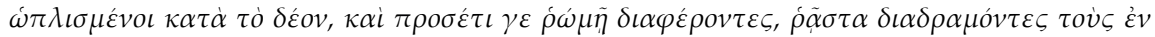

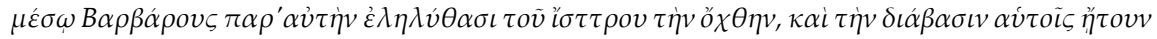

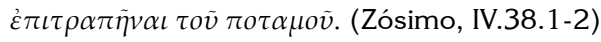


autoridades imperiales de frontera. El oficial a cargo, Prómoto, se negó. Lo interesante en relación al tema de este artículo se encuentra en los pasajes siguientes. En ellos, Zósimo describe que Prómoto decidió implementar un plan para engañar a estos greutungos y derrotarlos fácilmente. Para ello, contó con la ayuda de otros militares que conocían la lengua bárbara y que se encontraban sirviendo en el ejército romano: “...reuniendo algunos de sus hombres que entendían su lenguaje (...), los envió para tratar con los bárbaros como si ellos intentaran traicionar a su propio pueblo"29.

El relato finaliza con la traición que padecieron estos greutungos y cómo fueron derrotados por Prómoto gracias a la planificación que llevó a cabo para tal fin. Con posterioridad, el oficial comunicó al emperador sobre su triunfo pero Teodosio, en lugar de tomarlos como prisioneros, los dejó libres

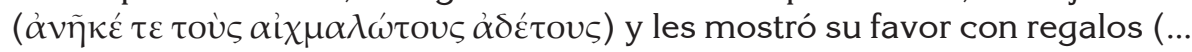

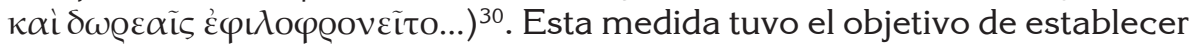
un acercamiento con este contingente, de manera que el emperador pudiese recurrir a ellos en eventos posteriores: Zósimo hace énfasis en que podrían resultar útiles en la campaña militar contra Magno Máximo ( $\kappa \alpha \tau \dot{\alpha} \alpha \ddot{\alpha} \lambda \lambda \omega \varsigma$

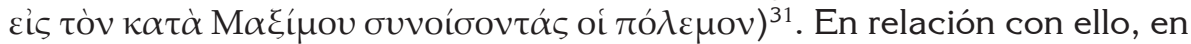
el segundo capítulo de su obra Contra Eutropio, Claudiano menciona que muchos de estos bárbaros (ostrogodos y greutungos, en sus palabras) cultivan la tierra frigia ${ }^{32}$. La referencia de Claudiano, si bien es empleada en un ataque contra Eutropio -el consul que había iniciado su carrera como praepositus sacri cubiculi del emperador Arcadio en Constantinopla-, podría estar reflejando parte de la realidad de la época ${ }^{33}$.

29 Zósimo, IV.38.2. Este pasaje resulta interesante, puesto que la mención de los soldados romanos que "entendían el lenguaje" de los bárbaros, podría interpretarse como una crítica, por parte de Zósimo, denunciando indirectamente la "barbarización" del ejército (dado que había soldados que conocían la lengua bárbara).

30 Zósimo, IV.39.5. A este respecto, Heather sostiene que hacia finales del siglo IV, los asentamientos de grupos bárbaros llevados a cabo por los romanos siempre incluían la subyugación del conjunto en cuestión, junto con su dispersión sobre un área geográfica amplia, a modo de minimizar el peligro potencial de una posible revuelta futura. Véase: HEATHER (2000: 21-22).

31 Zósimo, IV.39.5. Véase, además: LieBeschuetz (1990: 30); KuLIKоwSKI (2007: 152-153).

32 Ostrogothis colitur mixtisque Gruthungis Phryx ager: hos parvae poterunt impellere causae in scelus; ad mores facilis natura reverti. sic eat: in nostro quando iam milite robur torpuit et molli didicit parere magistro, vindicet Arctous violatas advena leges; barbara Romano succurrant arma pudori. (Claudio Caudiano, Contra Eutropio II, 153-159).

33 Zósimo, V.9.2. Véase, además: Jones (1964: 177-178). 
De esta manera, la modalidad de uso que el Imperio adoptó para con este contingente fue, aparentemente, la de instalar a los supervivientes en una región a cambio de que proporcionasen tropas para el Estado romano ${ }^{34}$. Tal como nos hace saber Zósimo, el objetivo de Teodosio era el de utilizar a estos efectivos como fuerzas de apoyo para combatir insurrecciones eventuales. Por lo general, las fuentes no ofrecen demasiada información específica acerca de las modalidades del uso de los soldados bárbaros. En este caso, en particular, podríamos suponer que estos greuguntos habrían sido incluidos en la categoría de laeti ${ }^{35}$. Sin embargo, las fuentes que describen la llegada de estos grupos no utilizan dicho término para referirse a los greuguntos aunque, si tenemos en cuenta que fueron vencidos y capturados e, incluso, establecidos en Frigia tras una batalla -como nos hace entender Claudiano-, bien podrían ser relacionados con esta problemática categoría ${ }^{36}$. La dificultad reside en que existen pocas menciones sobre estos laeti y, la gran mayoría de ellas ocurren en el contexto del imperio occidental ${ }^{37}$, de acuerdo a la Notitia Dignitatum ${ }^{38}$.

34 Burns, por ejemplo, en su clásico A History of the Ostrogoths, sostiene que la mayoría de estos greutungos que cruzaron el Danubio liderados por Odoteo fueron masacrados y muy pocos de ellos fueron realmente establecidos en Frigia gracias al apoyo de Teodosio (que buscaba conseguir más efectivos para sus campañas militares). Para Burns, este evento fue, quizás, el único de gran relevancia que llevó a cabo esta gens en territorio romano hacia finales del siglo IV. Véase: Burns (1984: 44).

35 Véase nota 2.

36 Normalmente, la categoría de laetus se encuentra relacionada con las instancias del reclutamiento de bárbaros. El problema reside en que estos efectivos recibían, muchas veces, otras denominaciones. Véase: JonEs (1964: 620); Elton (1997: 129-130).

37 Por ejemplo, en la Pars Occidentis de la Notitia Dignitatum de Occidente figuran varias unidades al mando de un Praefectus Laetorum. Véase: Not. Dig. Occ., XLII. Para este documento, sigo la edición de SEECK (1876). De acuerdo con Southern, los laeti podían ser encontrados, originalmente, en Italia y Galia. Véase: Southern y Dixon (1996: 48).

38 La Notitia Dignitatum recopila la totalidad de los cargos militares y administrativos del imperio tardío, como así también todas las unidades militares del imperio y los lugares en los que estaban asentadas, en teoría, al momento de su compilación. El debate en torno a las fechas de composición de la Notitia continúa hasta el día de hoy. A modo de sintetizar las discusiones, podemos mencionar que J. B. Bury afirmó que el documento íntegro representó el estado del mundo romano alrededor del año 438. A. H. M. Jones, por su parte, señaló que la lista oriental fue reformada varias veces hasta la muerte de Teodosio (395) y el listado occidental lo hizo hasta el fallecimiento del emperador Honorio (423). Finalmente, Michael Kulikowski afirmó que la redacción correspondiente a la parte oriental puede ser fechada en 394, un tiempo antes de la batalla del Frigidus, mientras que aquélla relativa a la mitad occidental fue enmendada hasta 419 e, incluso, algún tiempo más tarde. Véase: BuRY (1920: 131-154); SALISBURY (1927: 102-106); JonEs (1964: 347, 349); Mann (1991: 215-219); KuLiкоwsкi (2000: 358-377). 


\section{Las fronteras externas y Constantinopla: los casos de Fravita y Uldin}

Para el estudio del uso de grupos bárbaros reducidos a comienzos del siglo V, hemos seleccionado dos casos, en orden cronológico: el de los federados hunos al mando del jefe Uldin y el de los federados godos bajo las órdenes de Fravita ${ }^{39}$. Podemos decir que las fuentes describen el accionar de estos personajes en relación a la revuelta de Gaïnas, que tuvo lugar en 399 y afectó, principalmente, a la ciudad de Constantinopla. El primero de estos hombres fue el líder de un grupo de hunos ${ }^{40}$ aunque, como afirma Otto Maenchen-Helfen, no fue el rey de toda esta gens ${ }^{41}$. En el caso de Fravita, la mayoría de los documentos que narran este acontecimiento lo caracterizan como a un bárbaro o como a un godo ${ }^{42}$. Este hombre realizó una carrera militar en el ejército romano y logró ascender a la posición de magister militum en el imperio oriental ${ }^{43}$.

Con anterioridad a estos acontecimientos, Fravita ya había establecido una alianza con el emperador Teodosio. Zósimo lo describe en el contexto de un banquete que había ofrecido el gobernante romano para negociar con el citado Fravita y con otro líder bárbaro, Eriulfo ${ }^{4}$. Ambos personajes representaban actitudes opuestas hacia el imperio: Fravita era partidario de respetar sus juramentos hacia el Estado romano (

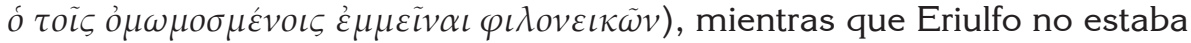
de acuerdo con ello y pensaba en alentar a los suyos a romper los acuer-

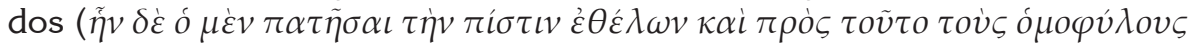

39 En este trabajo utilizaremos la forma "Fravita" para referirnos a este personaje. Las fuentes

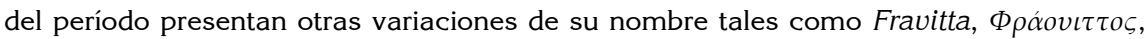
Fravitus y $\Phi \rho \alpha ́ \beta \iota \theta o \varsigma$, por nombrar algunos ejemplos. Véase: SCHÖNFELD (1911: 92-93).

40 Timo Stickler señala que Uldin es el primer phylarchos huno del que tenemos mención en las fuentes del período. Para este historiador, Uldin había logrado consolidar un dominio similar al de un reino, abarcando comunidades hunas como no-hunas. Véase: STICKLER (2007: 53). Guy Halsall y Wolf Liebeschuetz tienen posiciones similares acerca de este personaje: durante esta etapa, Uldin habría sido el gobernante de gran parte de los territorios situados al norte del Mar Negro. Véase: Halsall (2007: 201); Liebeschuetz (1990: 37).

41 Maenchen-Helfen (1973: 62).

42 Sozomeno, Eunapio y Zósimo lo presentan como un bárbaro. En cambio, Sócrates lo caracteriza como un godo. Véase: Sozomeno, VIII.4, Eunapio, 69.4; Sócrates, VI.6; Zósimo IV.56.1. Para la obra de Sozomeno, sigo las ediciones de HANSEN (2013) y de HusSEY (1860). Para el texto de Sócrates de Constantinopla, sigo la edición de Hussey (1853).

43 Jones (1971: 372).

44 Es interesante la descripción del fragmento 59 del texto de Eunapio de Sardes (de acuerdo con la edición de R. C. Blockley), en el cual, la figura de Fravita es descrita con mayor profundidad. En tal sentido, Eunapio afirma que Fravita manifestó abiertamente ante Teodosio que era un practicante de la religión antigua. De manera similar, pidió al emperador permiso para contraer matrimonio con una mujer romana, permiso que Teodosio

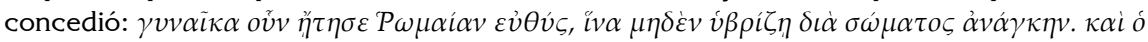

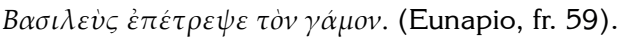


$\left.\pi \alpha \rho \alpha \kappa \alpha \lambda \tilde{\omega} v{ }^{\prime} E \rho i ́ o v \lambda \varphi \circ \varsigma\right)^{45}$. De tal manera, tras dejar el banquete, ambos caudillos discutieron a raíz de los efectos del alcohol. Finalmente, Fravita perdió el control y asesinó al mencionado Eriulfo, con lo cual, el primero se convirtió en un aliado fiel de los romanos a partir de ese momento, de acuerdo a lo que nos dicen otras fuentes contemporáneas que abarcan el período ${ }^{46}$. De hecho, en el marco de la revuelta de Gaïnas, Fravita fue designado como magister utriusque militiae por las autoridades de la corte oriental para detener a este líder godo ${ }^{47}$.

Con respecto al episodio de la insurrección de Gaïnas en Constantinopla, nuestra fuente principal para estos hechos es la Nueva Historia, de Zósimo ${ }^{48}$. El historiador bizantino alude a que Gaïnas -un militar godo que había servido a las órdenes de Teodosio en la batalla del Frigidus, en $394^{49}$-, intentó llevar a cabo un complot para dominar Constantinopla.

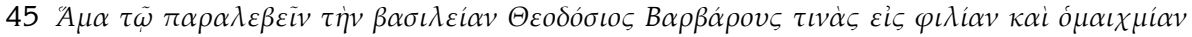

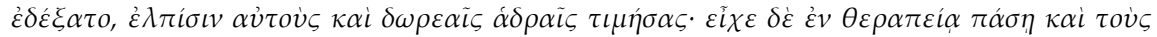

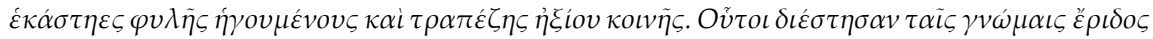

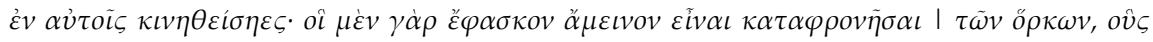

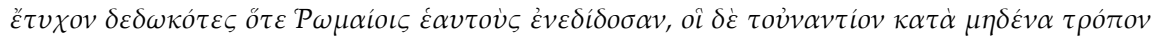

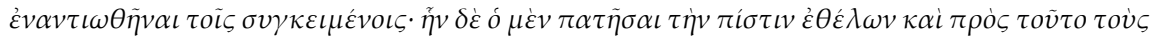
ó (Zósimo, IV.56.1-2).

46 Como ocurre en el caso de los historiadores eclesiásticos Sócrates de Constantinopla y Sozomeno. Véase: Sócrates. VI.6, Sozomeno. VIII.4.

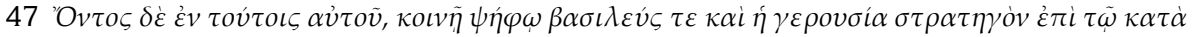

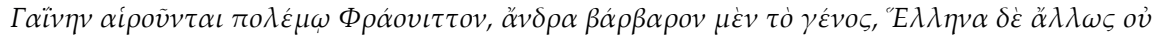

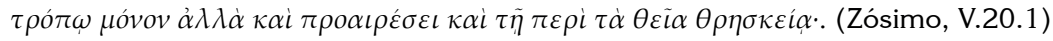

$48 \mathrm{El}$ autor de la Nueva Historia fue comes y abogado del fisco en la administración del imperio oriental y compuso su historia entre 498 y los años 518-527, aproximadamente. Para su redacción, el escritor utilizó la obra de Dexipo, al menos en lo que atañe a su libro primero. En segundo lugar, recurrió a la citada historia de Eunapio, desde el libro II hasta el capítulo 27 del V. Por último, empleó la narración de Olimpiorodo para el resto de su trabajo -que concluye con la deposición de Prisco Atalo en el capítulo 10 del libro VI-. Los dos temas principales en su narrativa son el declive del paganismo y la barbarización del imperio: Zósimo criticó a los emperadores cristianos y la expansión de esta fe. Por lo demás, se muestra contrario al enrolamiento de bárbaros en el ejército -en una postura similar a Eunapio-. Véase: PAschoud (1971: XVII); CANdAu Morón (1992: 7-9); Ridley (1982: XII-XIII).

49 El autor de Constantinopla se refirió a Gaïnas en vísperas de la batalla del Frigidus, explicando que estaba al mando de los auxiliares bárbaros junto a Saúl y Bacurio, otros

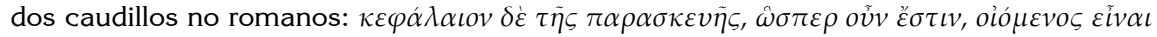

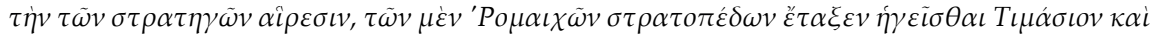

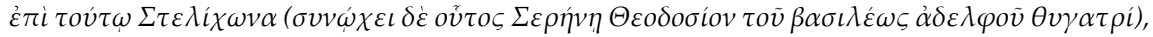

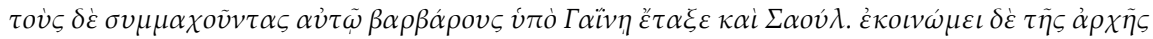

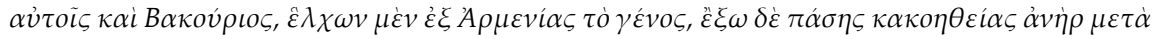

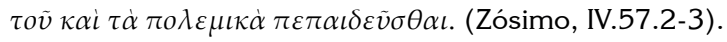


Para ello, pactó con su pariente, el godo Tribigildo ${ }^{50}$, quien se encontraba al mando de las tropas de caballería, en Frigia ${ }^{51}$. Pese a sus esfuerzos, el plan de Gaïnas resultó fallido y huyó de la capital oriental para ocultarse en Tracia. Cuando intentó cruzar el Helesponto, fue interceptado por las fuerzas de Fravita. Según la narración de Zósimo, el oficial de origen bárbaro atacó a los botes de Gaïnas y derrotó a la gran mayoría de sus soldados, aunque dejó escapar con vida al caudillo enemigo ${ }^{52}$.

Con posterioridad, el mencionado Gaïnas pereció a manos de otro grupo bárbaro. El jefe huno Uldin se encontraba próximo a la frontera del Danubio con sus hombres y no habría permitido que Gaïnas se acercase con su ejército, probablemente debido a que no creía conveniente la proximidad de una comunidad ostrogoda a la suya ${ }^{53}$. Es por ello que el caudillo huno persiguió a Gaïnas y lo asesinó, siendo recompensado por el emperador de Oriente a raíz de este hecho ${ }^{54}$. A partir de ese momento, el líder bárbaro logró establecer un acuerdo con las autoridades romanas, beneficiándose de esta situación, puesto que se le habría proporcionado una cierta autonomía para llevar a cabo acciones al otro lado del Danubio ${ }^{55}$.

Ahora bien, Uldin también aparece mencionado en las Historias contra los Paganos, de Orosio. El escritor de Hispania afirmaba que Uldin participó junto con Saro (otro jefe godo que estaba al mando de tropas federadas sirviendo al imperio, del que hablaremos en los siguientes apartados) y Estilicón, en la campaña militar destinada a detener la invasión del caudillo godo Radagaiso, acaecida en el año 406:

Para repeler a Radagaiso, ese adversario monstruoso, otros enemigos nuestros con sus tropas se inclinan voluntariamente para el auxilio: están presentes Uldin y Saro, los duques de los hunos y godos, para la ayuda de los romanos... ${ }^{56}$.

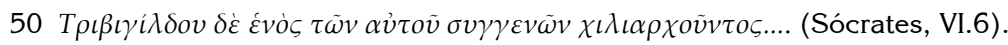

51 LieBESCHUETZ (1990: 34).

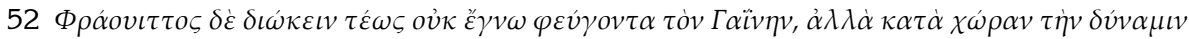

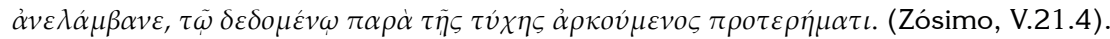

53 Zósimo, V.22.1. Véase, además: MaEnchen-Helfen (1973: 59).

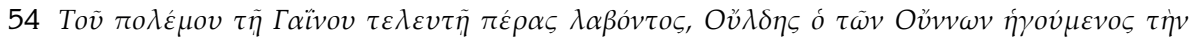

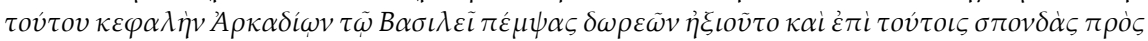

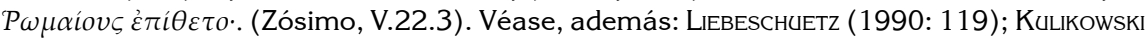
(2007: 169).

55 Wolfram (1990: 150).

56 Conceduntur quidem aduersus immanissimum illum hostem Radagaisum aliorum hostium cum copiis suis inclinati ad auxilium animi: adsunt Vldin et Sarus, Hunorum et Gothorum duces, praesidio Romanorum; sed non sinit Deus rem potentiae suae uirtutem hominum ac maxime hostium uideri. (Orosio, VII.37.12). Para la obra de Orosio, sigo la edición de ARNAUd Lindet (1991). 
Podemos sugerir que los ejemplos de estos dos personajes (Fravita y Uldin) comandando bárbaros estarían representando dos modos distintos en lo concerniente al empleo de estos efectivos, como así también dos momentos diferentes en la historia de las relaciones entre el imperio y estas gentes. En primer lugar, tenemos el caso de Fravita: un líder bárbaro, probablemente de origen godo, que decidió mantener sus juramentos hacia los romanos y, según lo que nos dicen las fuentes, fue siempre fiel a los emperadores, pese a haber sido practicante de la religión imperial antigua ${ }^{57}$. Debido a esto último, podríamos sugerir que Fravita fue un militar que poseía contactos fluidos con la cultura romana: prueba de ello es la recompensa que pidió al emperador Arcadio tras vencer a Gaïnas, esto es, el permiso para profesar la religión pagana ${ }^{58}$. De cualquier manera, esto bien podría ser una crítica indirecta de Eunapio hacia Teodosio y su entorno cristiano: aquél que pudo detener a Gaïnas era, justamente, un practicante del paganismo antiguo, más no un militar perteneciente a los círculos cristianos. Probablemente para Eunapio, esto era otra prueba de que el abandono de la religión tradicional fue una medida equivocada.

Como podemos apreciar, las autoridades utilizaron los servicios de Fravita de una manera determinada: enviarlo a combatir contra los godos disidentes que se encontraban al mando de Gaïnas. Por otro lado, la figura de Uldin y sus jinetes hunos representaría lo que podríamos definir como un contingente cuyos vínculos con la cultura y políticas imperiales habrían sido más reducidos. Es probable que, por estos motivos, Uldin haya sido requerido por breves períodos por las autoridades de Constantinopla y, en general, su campo de acción habría estado más vinculado a los territorios situados más allá de la frontera que dentro del imperio mismo ${ }^{59}$. Pensemos, por ejemplo, en el episodio en el cual derrotó a Gaïnas y lo asesinó: fue el punto de partida de una relación entre el Estado romano y los hunos que luego se volvería inestable en los años siguientes (Uldin rompió los acuerdos en varias ocasiones ${ }^{60}$ ).

57 Martindale (1980: 373).

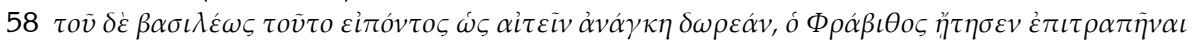

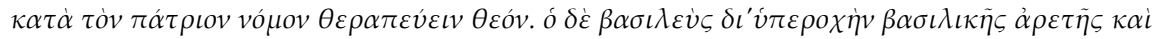

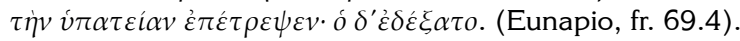

59 HEATHER (2006: 196).

60 Uldin fue el protagonista, asimismo, de dos incursiones de saqueo a inicios del siglo V. La primera de ellas tuvo lugar en 405, cuando invadió Tracia. La segunda, en 408, cuando volvió a atacar la misma provincia. En esta última oportunidad, las fuentes mencionan que perdió gran parte de sus seguidores debido a que se rehusó a negociar nuevamente con las autoridades imperiales. Véase: Sozomeno, VIII.25, IX.5. 


\section{Saro y su contingente de godos de élite}

Saro fue otro líder godo que sirvió, junto con sus seguidores, como federado para el Imperio romano a comienzos del siglo V. Como analizaremos a continuación, el caso de Saro resulta interesante debido a que su figura es descrita de diversas maneras en las fuentes del período. Algunas de ellas lo presentan comandando numerosos contingentes mientras que otros textos lo caracterizan guiando pequeños unidades.

La primera referencia que tenemos sobre él la encontramos en la obra de Orosio, quien especifica que contaba con el cargo de dux Gothorum, en el marco de la invasión de Radagaiso, como ya mencionáramos en el apartado correspondiente a Fravita y Uldin ${ }^{61}$. De los testimonios vinculados a la invasión de Radagaiso, otra mención de Saro estando entre los aliados de Estilicón se encuentra en la más tardía crónica del conde Marcelino ${ }^{62}$ :

Huldin y Saro, los reyes de los hunos y de los godos, derrotaron a Radagaiso inmediatamente, su cabeza fue cortada, sus seguidores son capturados y vendidos por un áureo ${ }^{63}$.

No podemos precisar con exactitud cuál era el número de adherentes que estaban a las órdenes de Saro en esta ocasión pero, si tenemos en cuenta que la mayoría de los testimonios caracterizan al contingente de Radagaiso como muy numeroso ${ }^{64}$, es probable que haya estado al man-

61 La campaña contra Radagaiso tuvo lugar en el 406, siendo este caudillo otra figura con orígenes desconocidos, aunque Burns estima que habría sido un ostrogodo y sus seguidores habrían pertenecido a numerosas comunidades. Véase: BuRNs (1984: 46). En este sentido, debemos recordar que las Historias contra los paganos fueron compuestas alrededor de 417, tras el regreso de Orosio desde África a Hispania. Véase: SÁnchez Salor (1982: 15). Respecto al cargo de dux Gothorum con el que es descrito Saro, una reciente e interesante interpretación fue propuesta por Jeroen Wijnendaele, quien busca probar que el mismo Saro, en un principio, habría formado parte del contingente de Radagaiso, liderando una de las tres divisiones del ejército de este caudillo. El autor señala que las fuerzas que lideraba Saro habrían ayudado a derrotar a Radagaiso una vez este se rindió. Véase: WIJNENDAELE (2016: 274-275).

62 El conde Marcelino compuso su obra en Constantinopla, entre los años 550 y 551 y abarcaba un análisis de los años 379 a 518. Con posterioridad, el mismo Marcelino realizó una actualización de su texto, ampliándolo hasta los sucesos del año 534. Véase: CROKE (1995: XIX).

63 Huldin et Sarus Hunnorum Gothorumque reges Radagaisum continuo devicerunt, ipsius capite amputato, captivos eius singulis aureis distrahentes. (Crónica de Marcelino, 406). Para este texto, sigo la edición de CROKE (1995).

64 Por ejemplo, Orosio señaló que el contingente de Radagaiso estaba conformado por 200.000 hombres (nam fuisse in populo eius plus quam ducenta milia Gothorum ferunt). El conde Marcelino procedió de manera similar en su obra: cum ducentis milibus suorum 
do de un ejército de proporciones considerables ${ }^{65}$. Esta información puede ser complementada con la que proporciona Zósimo: al referirse a los eventos posteriores a la muerte de Estilicón, en 408 (cuando Alarico no se decidía a llevar la guerra contra el emperador Honorio), el historiador bizantino afirmaba que Saro poseía experiencia en las cosas de la guerra

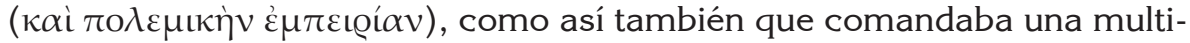

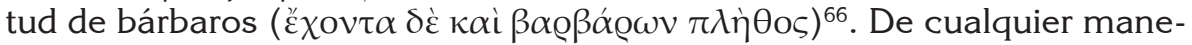
ra, parecería que en el marco de esa campaña militar, Saro se encontraba al mando de tropas bárbaras y romanas ${ }^{67}$. Con posterioridad, él participaría de las expediciones militares llevadas a cabo en el marco de la usurpación de Constantino III (407-411), probablemente liderando un grupo con composición similar. En efecto, el líder bárbaro era un partidario de Estilicón, con lo cual, fue enviado a asediar la ciudad de Arles, urbe que logró asaltar derrotando a Justiniano -uno de los magister militum designados por el insurrecto Constantino- ${ }^{68}$. De tal manera, este jefe representaría el papel clásico de un líder de federados del Imperio tardío siendo respaldado por una personalidad de relevancia en el ámbito político-militar, como lo era Estilicón.

Ahora bien, al analizar otros testimonios que hacen referencia a las actividades de este caudillo bárbaro en años posteriores a la muerte de Estilicón, su ejército es caracterizado como más reducido. Por ejemplo, Sozomeno describió a Saro como un bárbaro y como un hombre muy en-

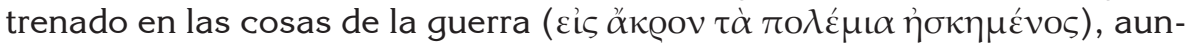
que no como un godo ${ }^{69}$. Otro dato interesante en el testimonio del escritor eclesiástico yace en la cifra de guerreros que comandaba Saro: sólo 300

totam Italiam inundavit, aunque probablemente haya tomado esta información de las Historias de Orosio. Véase: CROKE (1995: XXII-XXIII).

$65 \mathrm{Al}$ respecto, Heather sugiere que el ejército de Radagaiso estaba conformado por varios pueblos y grupos, de los cuales, los que ejercían el liderazgo de la confederación habrían sido godos. Por lo demás, el autor añade que, si bien no sabemos la cifra exacta, es muy probable que el contingente haya estado conformado por más de 10000 guerreros. Por su parte, Wolfram considera que se trataría de una figura similar a la de un rey bárbaro arcaico, que no contaba con el reconocimiento ni de los romanos ni de los hunos (y he aquí el motivo por el cual ambas facciones unieron fuerzas para derrotarlo). Véase: HEATHER (1994: 14, 88); Wolfram (1990: 170).

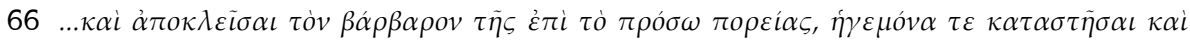

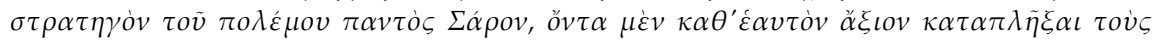

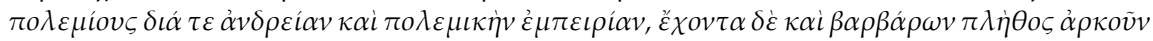

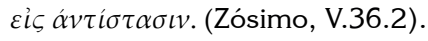

67 Martindale (1980: 978).

68 ARCE (2007: 35); DRINKWATER (1998: 278).

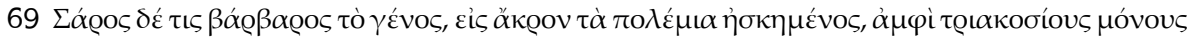

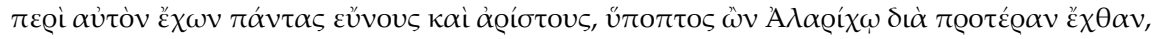

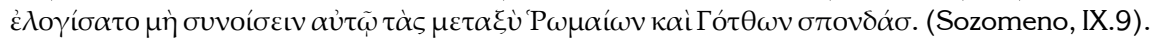


aunque, como señala el autor, todos ellos bien preparados y excelentes

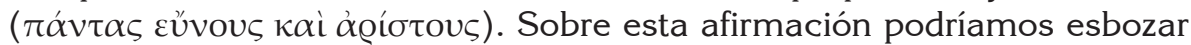
algunas interpretaciones. En primer lugar, si tenemos en cuenta el número de seguidores de Saro en esta etapa ${ }^{70}$, como así también la caracterización de sus tropas en las fuentes (como muy especializadas), podríamos sugerir que el caudillo godo habría estado al mando de un contingente de guerreros bucelarios ${ }^{71}$ : unidades de élite que servían a personalidades importantes del ámbito castrense o civil, por lo general, de manera privada ${ }^{72}$.

Esta interpretación también puede ser complementada por los testimonios de Olimpiodoro: en otro fragmento perteneciente a su obra, el

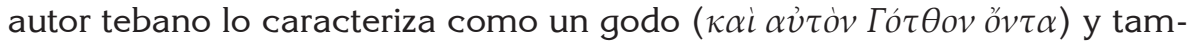
bién lo describe como "gobernando una multitud pequeña" ( $\kappa i i \pi \lambda \dot{\eta} \theta o v \varsigma$

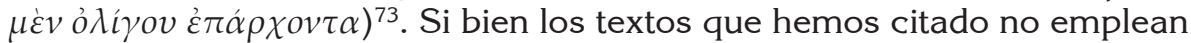
los términos comúnmente usados para referirse a este tipo de guerreros, si analizamos brevemente la carrera de este militar, podríamos encontrar más sustento para argumentar que estuvo al mando de un contingente de bucellarii ${ }^{74}$, al menos durante sus últimos años al servicio del Imperio. En dicha carrera, se destaca su vinculación a las estructuras imperiales. Los títulos militares con los que es descrito en las fuentes (dux y, posiblemen-

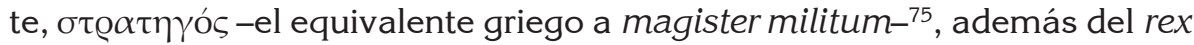
que hace referencia al liderazgo de una gens $\left.^{76}\right)$, sugieren que se trataría de un hombre que, hacia el 405/406, ya habría participado en el ejército romano con los suyos durante algunos años. A partir de este planteamiento, podemos sugerir que Saro había aprendido tácticas militares y habría esta-

70 En este sentido, Candau Morón afirma que el ejército de Saro no habría sido demasiado numeroso, puesto que se retiró del asedio de Valentia cuando llegaron Edobico y Geroncio, los generales subordinados del usurpador Constantino III. Además, en su retirada a Italia, Saro prefirió pagar a los bagaudas para que le permitiesen cruzar los Alpes, en lugar de enfrentarlos en combate. Véase: CANdau Morón (1992: 512).

71 Olimpiodoro explicaba que bucellarii era un apodo que aplicaba a los soldados que consumían buccellatum, esto es, un tipo de pan seco. Olimpiodoro, fr. 7.4, 12. Para los fragmentos de la obra de Olimpiodoro de Tebas, sigo la edición de BLOCKLEY (1983).Véase, además: Schмiтt (1994: 149-150).

72 Elton (1997: 102); SOUthern y Dixon (1996: 49, 65).

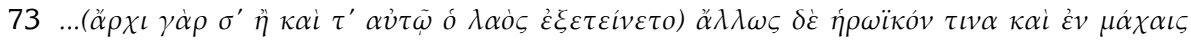

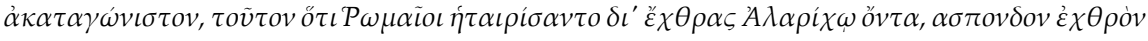

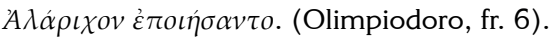

74 Diesner (1972: 322-323); Schmitt (1994: 151).

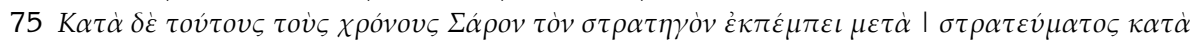

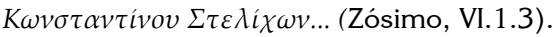

76 Jones señala, por ejemplo, que Saro y los suyos habrían formado parte del contingente de Alarico, en un primer momento. El caudillo godo habría dejado el grupo principal tras la derrota que sufrieron los visigodos en la batalla de Verona, en 402. Véase: JonEs (1964: 186); Wolfram (1990: 169). 
blecido contactos con parte de la jerarquía militar imperial ${ }^{77}$. En este sentido, cabe recordar que los bucelarios servían de manera privada a los altos oficiales (civiles y militares) y, a partir de estas funciones, se establecía un lazo de unión entre ellos y su patrón ${ }^{78}$. Por estos motivos, para poder desempeñarse de esta manera, Saro tendría que haberse ganado la confianza de figuras importantes, siendo Estilicón el ejemplo más representativo ${ }^{79}$.

A partir de los ejemplos analizados, podríamos sugerir que Saro habría comenzado a servir como bucellarius de Estilicón tras separarse del contingente de Alarico y, con el paso del tiempo, el citado Estilicón le habría conferido el mando de un ejército más grande durante el desarrollo de la invasión de Radagaiso y la usurpación de Constantino III. Con la muerte del general, en 408, Saro habría regresado a su papel de conductor de una banda armada más pequeña, al mejor estilo de los bucellarii que ya hemos descrito. En este sentido, es probable que Estilicón le haya confiado a Saro el mando de un cuerpo militar más amplio debido al vínculo de confianza que se estableció entre ambos, además de los buenos resultados que el líder godo obtuvo durante las campañas militares en las que participó.

\section{Consideraciones finales}

El imperio romano del siglo $\mathrm{V}$ de nuestra era se caracterizó por varios problemas relacionados con los asuntos de política interior y con los factores económicos. Como ya mencionamos en la introducción de este trabajo, los bárbaros pasaron a cumplir funciones militares a las órdenes del aparato estatal romano, cada vez con mayor asiduidad. A partir de lo analizado a lo largo de este artículo, podemos sintetizar los siguientes aspectos:

- Normalmente (y, en especial, durante el reinado de Teodosio), los bárbaros que realizaban incursiones y eran derrotados, terminaban siendo reclutados o integrados a la estructura militar del imperio romano. Esto se dio, particularmente, en el caso de los greutungos que hemos analizado. Se trataba de un contingente que provenía del mundo exterior al imperio, probablemente guiado por informaciones que se habían difundido tras la batalla de Adrianópolis sobre las ventajas de la vida en suelo romano ${ }^{80}$. Además, si bien el grupo habría sido de considerable tamaño (siempre tomando en cuenta las descripciones de los autores contemporáneos), tras la derrota sufrida por Prómoto, sus bajas habrían sido considerables. En este sentido, resulta interesante que Teodosio haya decidido integrar a los

77 Wolfram (1990: 11-14).

78 Probablemente debido a que los orígenes de la institución también se encontrarían relacionados con los domestici. Véase: Schmitт (1994: 154).

79 Diesner (1972: 327).

80 Heather (2010: 32-33). 
guerreros supervivientes en el ejército, estableciendo una alianza con ellos y asentándolos en Asia menor, en lugar de emplearlos como guardias en la frontera danubiana. Esto podría significar dos cosas desde el punto de vista estratégico. En primer lugar, podríamos considerar que el emperador deseaba reforzar su ejército para la ofensiva contra Magno Máximo (es la interpretación de Zósimo). En segundo término, Teodosio los habría instalado en Frigia (a juzgar por el testimonio de Claudiano) para tener tropas que pudiesen apoyar a aquellas apostadas en la frontera con Persia y, además, para evitar situar a unidades de origen bárbaro en el Danubio que facilitasen el ingreso de otros grupos extranjeros provenientes del exterior del limes en esa región. En suma, las estrategias de utilización de guerreros no-romanos continuaron prácticamente inalteradas tras la muerte de Teodosio.

Esto se debió a la necesidad de contar con numerosos efectivos debido a los problemas presentes en diferentes frentes (pensemos en las usurpaciones de inicios del siglo V, junto con las invasiones de Radagaiso y las migraciones de suevos, vándalos, alanos y burgundios hacia fines del 406). En este sentido, los bárbaros habrían representado una fuente importante de reclutas.

- El grado de contactos e intercambios con las estructuras del mundo mediterráneo también podía influir en el modo de utilización de estos grupos. Por ejemplo, en algunas ocasiones, aquellos contingentes que se encontraban menos influidos por la cultura romana tenían su rango de acción, aparentemente, por fuera del limes romano. Este fue el caso de Uldin, el líder huno que actuó en los territorios situados más allá del Danubio para detener al insurrecto Gaïnas y que, gracias a estas acciones, logró el favor del imperio oriental durante algunos años. Con posterioridad, si bien Uldin integró la fuerza que detuvo al caudillo Radagaiso, en 406, el líder huno rompió acuerdos con los romanos y realizó incursiones en territorios situados en el imperio oriental.

La contrapartida a esta situación estaría representada por aquellos grupos que poseían un grado mayor de vinculación a las estructuras imperiales: es posible sugerir que dichos grupos se desempeñarían dentro del territorio romano. En este apartado podríamos mencionar a la figura de Fravita (que bien podría ser considerada como opuesta a la de Uldin): un oficial de origen godo "romanizado" y practicante de la religión pagana imperial tradicional, que comandaba soldados bárbaros en el imperio de Oriente y que, asimismo, contrajo matrimonio con una mujer romana. El caso de Fravita es interesante puesto que representaría el arquetipo a seguir por los líderes bárbaros que deseasen desempeñarse en las filas del ejército romano: un godo leal al imperio que pudo escalar en la jerarquía militar e, incluso, llegó a ser recompensado y recibió privilegios (como el de profesar la fe pagana). 
Otro ejemplo similar al de Fravita es el de Saro. Como mencionamos con anterioridad, en un comienzo Saro habría pertenecido al contingente de Alarico, hasta desertar con los suyos debido a una rivalidad (que continuó hasta los tiempos del liderazgo de Ataúlfo, el cuñado de Alarico). Desde su alejamiento del gran contingente visigodo, Saro logró acercarse más a las estructuras políticas y militares del imperio, siendo una consecuencia de este acercamiento su participación en dos campañas militares importantes que fueron dirigidas por Estilicón a comienzos del siglo V. Tras su accionar en ambas campañas, Saro se habría desempeñado como bucellarius y partidario del citado Estilicón, aspecto que le posibilitó ganarse la confianza del magister utriusque militiae de Occidente. Finalmente, Saro se alejó del servicio al Estado romano luego de la muerte del mencionado general (en 408), debido a que el emperador Honorio prefirió aliarse con Ataúlfo. De tal manera, este militar con orígenes no-romanos fue descartado de la política imperial, aunque su base de poder habría continuado estructurada a la manera de los bucellarii hasta su muerte a manos de Ataúlfo (esto es, un grupo reducido de guerreros altamente especializados).

- Debemos tener en cuenta que estas representaciones de los bárbaros pactando continuamente con los romanos, controlando la defensa de zonas de frontera o llevando a cabo operaciones en ciertos territorios del interior del imperio fuesen, en muchas ocasiones, una crítica de los autores del período hacia la debilidad del Estado y las malas políticas de los gobernantes del siglo V y sus ministros. Pensemos, por ejemplo, que en tiempos del emperador Teodosio se le permitió el ingreso a los greutungos liderados por Odoteo, con su consiguiente instalación dentro de las fronteras del imperio, emperador que se destacó -a ojos de ciertos escritores que analizan esta etapa- por sus malas políticas al favorecer a los bárbaros. Además, durante el reinado de Arcadio (otro gobernante que generalmente es retratado con mala imagen por los contemporáneos) tuvo lugar la revuelta de Gaïnas, quien fue detenido por la acción conjunta de dos líderes no-romanos (los mencionados Fravita y Uldin). Para Occidente, contamos con el ejemplo similar de Saro, quien había sido contratado por Estilicón, un general que tampoco era bien visto por algunos de los autores del período (a excepción de Claudio Claudiano). Por lo demás, Saro comandaba un contingente numeroso en un primer momento, según el testimonio de Zósimo: teniendo en cuenta lo que ya mencionamos antes, este dato podría representar otra crítica hacia el filobarbarismo de estos emperadores de fines del siglo IV y comienzos del V. Es probable que la audiencia constantinopolitana de Zósimo desease, durante el siglo VI, leer información referente a grandes grupos de guerreros bárbaros moviéndose libremente y sin impedimento por el antiguo Occidente romano, prueba de la debi- 
lidad del Estado en esa jurisdicción (a diferencia de lo que ocurrió con el Oriente, que permaneció como foco de la ideología imperial en el siglo VI)

En este contexto complejo de inicios del siglo V, algunas comunidades bárbaras lograrían consolidar su dominio sobre ciertos territorios que les fueron concedidos por el Estado romano, iniciando procesos de construcción ideológica e identitaria que reunirían la influencia de la civilización mediterránea con los rasgos propios de las culturas bárbaras. Otras gentes, en cambio, se abrirían paso en la carrera militar del ejército romano, haciéndose eco de la cultura latina que, en ocasiones, tanto llegaba a fascinarles. Todo ello en un proceso que, si bien se había iniciado ya a comienzos del siglo IV, cobraría más fuerza en el desarrollo de la segunda mitad de la centuria, luego de la re-configuración de las estructuras y jerarquías bárbaras situadas más allá del Danubio, proceso que tuvo lugar con la llegada de los hunos ${ }^{81}$. En suma, se trata de una etapa en la que el análisis del uso de contingentes bárbaros, ya sean reducidos o de grandes magnitudes, asimilados o no al Estado romano, puede ayudarnos a arrojar algo de luz para comprender el complejo contexto del siglo $\mathrm{V}$ y de la transformación del mundo romano.

\section{Bibliografía}

ArCE, J. (2007) Bárbaros y Romanos en Hispania. 400-507 A.D, Madrid. Arnaud Lindet, M. P. (ed. y trad.) (1991) Orose. Histoires (Contre les Païens), Paris.

Bachrach, B. S. (1973) A History of the Alans in the West. From Their First Appearance in the Sources of Classical Antiquity through the Early Middle Ages, Minneapolis.

Blockley, R. C. (2008) "The Dynasty of Theodosius", en The Cambridge Ancient History Vol. XIII. The Late Empire, A.D. 337-425, pp. 111-137. BlockLEy, R. C. (ed. y trad.) (1983) The Fragmentary Classicising Historians

of the Later Roman Empire. Eunapius, Priscus, Olympiodorus and Malchus. Vol. II: Text, Translation and Historiographical Notes, Liverpool. Burgess, R. W. (ed. y trad.) (1993) The Chronicle of Hydatius and the Consularia Constantinopolitana. Two Contemporary Accounts of the Final Years of the Roman Empire, Oxford.

Burns, T. S. (1984) A History of the Ostrogoths, Indianapolis.

BurNs, T. S. (1994) Barbarians within the Gates of Rome: A Study of Roman Military Policy and the Barbarians, ca. 375-425 A.D, Indianapolis.

81 HEATHER (1995: 5). 
Bury, J. B. (1920) "The Notitia Dignitatum", Journal of Roman Studies, 10, pp. 131-154.

Candau Morón, J. M. (ed. y trad.) (1992) Zósimo. Nueva Historia, Madrid. CROKE, B. (ed. y trad.) (1995) The Chronicle of Marcellinus, Sydney.

Diesner, H. J. (1972) "Das Buccellariertum von Stilicho und Sarus bis auf Aetius (454/455)", Klio, 54, pp. 321-350.

Drinkwater, J. F. (1998) "The Usurpers Constantine III (407-411) and Jovinus (411-413)", Britannia, 29, pp. 269-298.

Elton, H. (1997) Warfare in Roman Europe, AD 350-425, Oxford.

Geary, P. J. (1988) Before France and Germany. The Creation and Transformation of the Merovingian World, Oxford.

GofFart, W. (1980) Barbarians and Romans A.D. 418-584. The Techniques of Accomodation, Princeton.

GuZmán Armario, F. J. (2000-2002) "Las externae gentes bajo los estandartes de Roma: asentamiento y reclutamiento bárbaros en las Res gestae de Amiano Marcelino", en Soldado y griego. Estudios sobre Amiano Marcelino [en línea], pp. 109-144. Disponible en: http://www. librosepccm.com/estudios/soldado-y-griego-estudios-sobre-amianomarcelino/ [acceso 16-XI-2016].

Halsall, G. (2007) Barbarian Migrations and the Roman West 378-569, Cambridge.

Hansen, G. C. (ed.) (2013) Sozomenus Kirchengeschichte, Berlin.

Heather, P. (2010) Empire and Barbarians. The Fall of Rome and the Birth of Europe, Oxford.

Heather, P. (1994) Goths and Romans 332-489, Oxford.

Heather, P. (1997) "Foedera and Foederati in the Fourth Century", en Kingdoms of the Empire. The Integration of Barbarians in Late Antiquity, pp. 57-74.

Heather, P. (2006) The Fall of the Roman Empire, Oxford.

Heather, P. (1995) "The Huns and the End of the Roman Empire in Western Europe", English Historical Review, 110.435, pp. 4-41.

Heather, P. (2000) "The Late Roman Art of Management: Imperial Defence in the Fourth Century West", en The Transformation of Frontiers: From Late Antiquity to the Carolingians, pp. 15-68.

Hussey, R. (ed.) (1853) Socratis Scholastici Ecclesiastica Historia, Oxford. Hussey, R. (ed.) (1860) Sozomeni Ecclesiastica Historia, Oxford.

Jones, A. H. M. (1964) The Later Roman Empire 284-602. A Social, Economic, and Administrative Survey, Oxford.

Jones, A. H. M.; MARTINDAlE, J. \& MoRRIS, J. (coords.) (1971) The Prosopography of the Later Roman Empire. Volume I A.D. 260-395, Cambridge.

KaISER, R. (2004) Die Burgunder, Stuttgart. 
Kulıкоwski, M. (2000) "The Notitia Dignitatum as a Historical Source", Historia: Zeitschrift für Alte Geschichte, 43.3, pp. 358-377.

Liebeschuetz, W. (1990) Barbarians and Bishops. Army, Church and State in the Age of Arcadius and Chrysostom, Oxford.

LieBeschuetz, W. (1993) "The End of the Roman Army in the Western Empire", en War and Society in the Roman World, Londres, pp. 265-276.

Liebeschuetz, W. (2006) "Warlords and Landlords", en A Companion to the Roman Army, pp. 479-494.

Maenchen-Helfen, O. J. (1973) The World of the Huns. Studies in their History and Culture, Los Angeles.

Mann, J. C. (1991) "The Notitia Dignitatum - Dating and Survival", Britannia, 22, pp. 215-219.

Martindale, J. R. (coord.) (1980) The Prosopography of the Later Roman Empire, Volume II A.D. 395-527, Cambridge.

O'Flynn, J. M. (1983) Generalissimos of the Western Roman Empire, Alberta. Paschoud, F. (ed. y trad.) (1971) Zosime. Histoire Nouvelle. Tomes I-V, Paris. Plautner, M. (ed. y trad.) (1990) Claudian Vol. I \& II, Cambridge (Massachusetts).

PoHL, W. (2002) "Ethnicity, Theory, and Tradition: A Response", en On Barbarian Identity. Critical Approaches to Ethnicity in the Early Middle Ages, pp. 221-239.

Ridley, R. T. (ed. y trad.) (1982) Zosimus. New History, Canberra. Rolfe, J. C. (ed. y trad.) (1935) Ammianus Marcellinus, Londres.

Salisbury, F. S. (1927) "On the Date of the 'Notitia Dignitatum'“, Journal of Roman Studies, 17, pp. 102-106.

Sánchez Salor, E. (ed. y trad.) (1982) Orosio, Historias, Madrid.

Sснмітт, O. (1994) "Die Buccellarii. Eine Studie zum militärischen Gefolgschaftswesen in der Spätantike", Tyche, 9, pp. 147-174.

SchöNfELD, M. (1911) Wörterbuch der altgermanischen Personen- und Völkernamen. Nach der Überlieferung das klassischen Altertums bearbeitet, Heidelberg.

Seeck, O. (ed.) (1876) Notitia Dignitatum Accedunt Notitia Urbis Constantinopolitanae et Laterculi Prouinciarum, Berlin.

Southern, P; Dixon, K. R. (1996) The Late Roman Army, Londres.

Southern, P. (2006) The Roman Army. A Social and Institutional History, Oxford.

Stickler, T. (2007) Die Hunnen, Munich.

Stickler, T. (2007a) "The Foederati", en A Companion to the Roman Army, pp. 495-514. 
Wheeler, E. L. (2007) "The Army and the Limes in the East", en A Companion to the Roman Army, pp. 235-266.

WiJnendaele, J. W. P. (2016) "Stilicho, Radagaisus, and the So-Called 'Battle of Faesulae' (406 CE)”, Journal of Late Antiquity, 9.1, pp. 267-284. Wolfram, H. (1990) History of the Goths, Los Angeles.

Wolfram, H. (2005) The Roman Empire and its Germanic Peoples, Los Angeles.

Fecha de recepción: 11-01-2018

Fecha de aceptación: 07-03-2018 